\title{
Relationship between Vertical Facial Pattern and Dental Arch Forms in Skeletal Class II Malocclusion
}

\author{
Dr. Ankur Sharma ${ }^{1}$, Dr. Aseem Sharma ${ }^{2 *}$, Dr. Apurva Vaidya ${ }^{3}$, Dr. Ambuj Chandana ${ }^{4}$, Dr. Nandita Sood ${ }^{5}$, Dr. Mayank \\ Mukhi $^{6}$ \\ ${ }^{1}$ M.D.S Orthodontics and Dentofacial Orthopedics and Ex Resident at Pt. J. L. N. G. M. C\&H Chamba Himachal Pradesh India \\ ${ }^{2}$ M.D.S Orthodontics and Dentofacial Orthopedics) and Senior Lecturer at Himachal Institute of Dental Sciences, Paonta Sahib Himachal Pradesh India \\ ${ }^{3}$ Postgraduate Student in Department of Pedodontics and Preventive Dentistry at Himachal Institute of Dental Sciences, Paonta Sahib Himachal Pradesh \\ India \\ ${ }^{4}$ M.D.S Orthodontics and Dentofacial Orthopedics Senior Lecturer at D.J Dental College Modinagar Uttar Pradesh India \\ ${ }^{5}$ M.D.S Orthodontics and Dentofacial Orthopedics and Senior Lecturer at Himachal Dental College Sunder Nagar, Himachal Pradesh India \\ ${ }^{6}$ M.D.S Orthodontics and Dentofacial Orthopedics Consultant Orthodontist at Delhi NCR Region India
}

DOI: 10.36348/SJODR.2019.v04i09.016

| Received: 11.09.2019 | Accepted: 20.09.2019| Published: 30.09.2019

*Corresponding author: Dr. Aseem Sharma

\section{Abstract}

Introduction: The purpose of this study was to investigate the relationship between vertical facial pattern and dental arch forms in class II skeletal malocclusion. Materials and Methods: The study comprised of 60 pretreatment (lateral cephalogram, dental cast and photographs) aged between 11-38 years full permanent dentition without agenesis and/or tooth loss except third molar. The evaluation of the dental arch form was performed using a computer analysis (AutoCad). Results: Assessment of interexaminar reliability analysis was performed using Kappa statistic. Pearson correlation was used to analyze the dental arch form and facial vertical dimensions. Conclusion: As the form of dental arches is associated with the vertical growth patterns, it would be desirable to use individualized arches for each patient.

Key words: Reliability, AutoCad, Photographs.

Copyright @ 2019: This is an open-access article distributed under the terms of the Creative Commons Attribution license which permits unrestricted use, distribution, and reproduction in any medium for non-commercial use (NonCommercial, or CC-BY-NC) provided the original author and source are credited.

\section{INTRODUCTION}

Dimensional changes in dental arches are compensatory mechanisms that occur as a result of growth and are required in order to maintain a balance between the functional and structural needs of the face and dentition [1].The dimensions of the dental arches change systematically during growth and development period, even if no treatment is administered [2]. The dimensions and morphology of the dental arches have considerable impact on orthodontic diagnosis and treatment planning, affecting space availability, dental esthetics, dentition stability and the prospects for a favorable development [3]. Soft tissues relating to the bones play an important role in the remodeling process. The factors that affect a patient's arch form and dimensions are dental perimeter, arch width, and arch depth.

One of the purposes of orthodontics is to correct malocclusion and position the teeth in ideal equilibrium with their bony bases. In an ideal occlusion the teeth are positioned in the greatest possible degree of harmony with their bony bases and surrounding tissues. Thus, during treatment planning it is important to observe the morphology of dental arch of each patient, since respect of its individuality will avoid periodontal problems, instability and deficiencies in the esthetic results. Hence preservation of form and dimensions of dental arches must be one of the first objectives of orthodontic problem. Arch dimensions are determined by arch width, arch length and arch depth. Arch width is measured as intercanine width, interpremolar width and intermolar width. Transverse expansion can change the arch perimeter along with increase in intercanine and intermolar width [2]. Arch form tends to return to its original form so the patient's existing arch form appears to be the best guide to the future arch form and stability [3].

Arch wires are the vital components of fixed orthodontic treatment [3]. Improper shaped archwires create many post treatment problems such as relapse or iatrogenic damage to teeth moved beyond their bony edges [4]. It can be accepted that in at least half of the patients the preformed arch wires don't seem to be functional. Because of these reasons, the routinely used superelastic preformed arch wires have to be in 
various forms with individual malocclusion adaptations. The fabrication of arch form in the canine and molar region should be planned in the proper way so as to prevent the instability of arch form[5,6] Orthodontic archwires are manufactured in different forms of dental arch in order to choose the most suitable ones for each patient. Therefore, orthodontic manufacturer produce different arch forms as archwires and it is difficult to choose the most suitable for our patients $[7,8]$.

Isaacson et al. reported that subjects with long faces showed decreased maxillary intermolar width [15]. The jaw transverse dimensions are also related to the vertical growth patterns. Long-face individuals have small skeletal transversal dimensions and individuals featuring short face have increased cross-sectional dimensions [1].

Clinicians often pay much attention to the inclination of the mandibular plane, because it is a major determinant of the vertical dimension of a face. A person with a steeper mandibular plane to cranial base often has a long anterior facial height, a smaller ratio of posterior to anterior facial height, and a short mandibular ramus height. Conversely, a person with a flat mandibular plane has a short anterior facial height, a larger ratio of posterior to anterior facial height, and a long mandibular ramus height $[11,12]$. The purpose of this study was to evaluate the relationship between vertical facial patterns and dental arch forms in skeletal class I malocclusions.

\section{MATERIALS AND METHOD}

The present study was carried out in the department of Orthodontics and Dentofacial Orthopaedics of Himachal Dental College and Hospital, Sundernagar (H.P). The sample consisted of 60 pretreatment records (lateral cephalogram, dental cast and photographs) aged between 11-38 years and the subjects were included in the study as per the following inclusion and exclusion criteria.

\section{INCLUSION CRITERIA}

- Full dentition except third molars.

- Pre-treatment lateral cephalogram, dental casts and digital photographs of dental cast.

- Individuals between 11-38 years of age.

\section{EXCLUSION CRITERIA}

- Previous orthodontic treatment

- Edentulous spaces

- Malformation

\section{MATERIALS USED FOR THE STUDY}

- Radiographs- Lateral Cephalogram.

- Dental casts and photographs

- AutoCad Software

\section{Method of tracing}

The radiographic films were covered on one side with the transparent cellulose acetate sheet. The tracings of the films were done using $3 \mathrm{H}$ lead pencil. In the lateral cephalograms, the ANB angle was measured according to the Steiner's[11]. ANB angle (Class IIANB $>4^{\circ}$ ). The subjects were further divided into three subgroups according to the values of angle SN-MP according to Schudy[12]: (1) low angle (MP-SN $<27^{\circ}$ ), (2) average angle (MP-SN $>27^{\circ}$ and $<36^{\circ}$ ), and (3) high angle $\left(\mathrm{MP}-\mathrm{SN}>36^{\circ}\right)$.

\section{DENTAL CAST ANALYSIS}

Shape of dental arch measurements was performed on digital photographs of patient plaster model. All the photos were taken by a single operator based on American Board of Orthodontics instructions with and the distance from the camera lens to the dental cast was recorded $20-25 \mathrm{~cm}$ for each cast.

The photo files were sent to AutoCad 2013 software. The evaluation of the dental arch form was performed using a computer analysis. The AutoCad software was used to draw a pentagon inscribed inside the arches as shown in figure I for maxilla and figure II for mandible.

\section{The following dental cast landmarks were used}

- Incisal point: The point in the midway between the incisal edges of two central incisors.

- Canine point: The cusp tip of right and left permanent canines.

- Mid central points of first permanent molars: by joining a line diagonally from cusp tip of mesiobuccal cusp to distopalatal cusp and a line from mesiopalatal cusp to distobuccal cusp and mid central point was made at the intersection of these two lines according to author Jucienne Salgado Ribeiro [13].

The following linear measurements were performed on maxillary and mandibular dental casts using computer analysis:

- Intercanine width the linear distance from cusp tip of one canine to the cusp tip of the other.

- Intermolar width the linear distance from mid central point of one permanent molar to the mid central point of other permanent molar.

- The angular measurements were performed on maxillary (Fig. I) and mandibular dental casts (Fig. II) forming a pentagon by using computer analysis. A vertex of the pentagon was placed between the two central incisors; two other vertices lie on the cusp of the canines, and the other two are placed at the center of first molars. Internal angles of the pentagon were measured as shown in Fig I and II.

The angular measurements (Ang1, Ang2R, Ang2L) representing the anterior arch form and angular 
Ankur Sharma et al; Saudi J Oral Dent Res, Sep 2019; 4(9): 657-665

measurements (Ang3R, Ang3L), representing the posterior arch form were evaluated. The ratio between the intercanine distance and the intermolar distance was calculated.
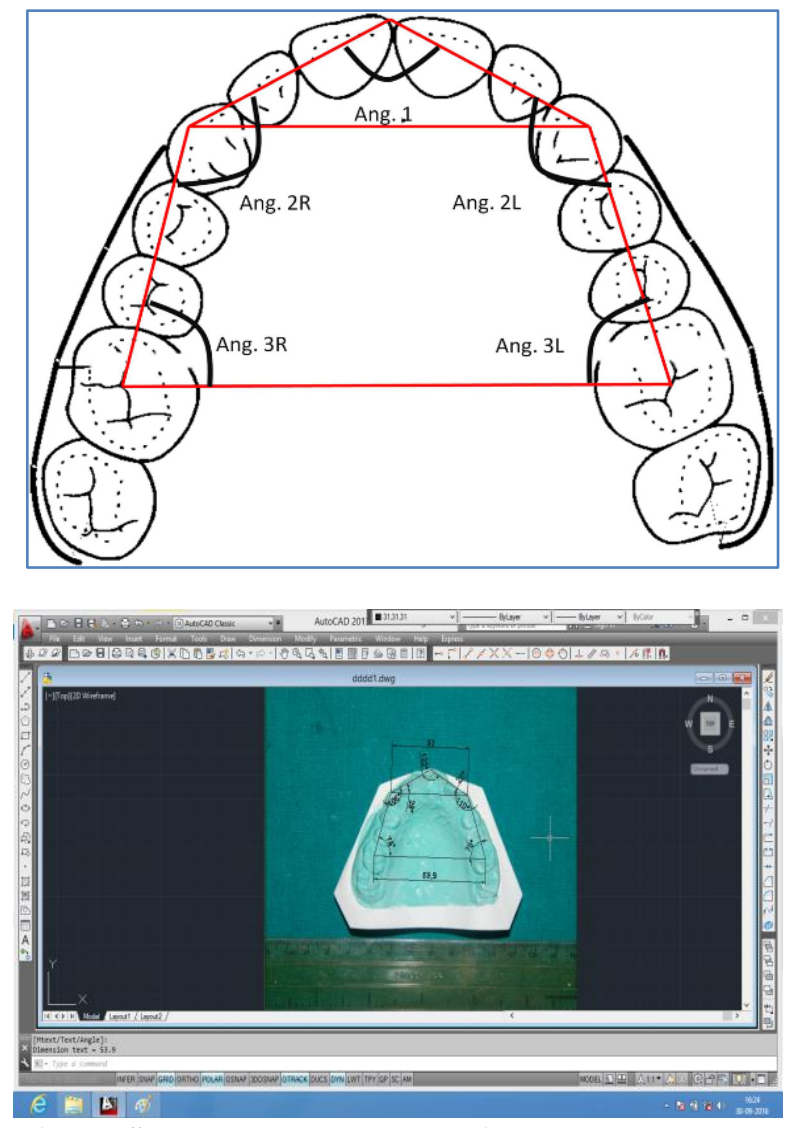

Fig-II: Shows the angular and linear measurements using computer analysis (AutoCad software) on the maxillary arch

\section{STATISTICAL ANALYSIS}

The analysis was performed on both dental arches, the upper and lower, in an independent manner. All the linear and angular measurements on the digital photographs of the plaster models and lateral cephalogram were made twice by same examiner to minimize the error of measurements. Assessment of interexaminar reliability analysis was performed using Kappa statistic. The interexaminer reliability was found to be Kappa $=.80-1.00(\mathrm{p}<0.001)$ which shows perfect agreement according to Landis and Koch. Pearson correlation was used to analyze the dental arch form and facial vertical dimensions in class I malocclusion using SPSS (Statistical package for social sciences) software.

\section{RESULT}

The study includes total 60 subjects. The subjects were further divided into three subgroups according to the values of angle SN-MP: (1) low angle $\left(\mathrm{MP}-\mathrm{SN}<27^{\circ}\right)$, (2) average angle $\left(\mathrm{MP}-\mathrm{SN}>27^{\circ}\right.$ and $\left.<36^{\circ}\right)$, and $(3)$ high angle $\left(\mathrm{MP}-\mathrm{SN}>36^{\circ}\right)$.
Table I and Table II shows the mean, the standard deviation, the standard error, the minimum and maximum value of different parameters of class II malocclusion in three different groups divided based on SN-MP angle (Low, medium and high angle).

The mean value of angle Ang I in class II maloclussion in different vertical facial patterns was 124.43 in low angle, 120.71 in average angle and 120.66 in high angle in maxillary arch and 134.29 in low angle, 131.29 in average angle and 134.71 in high angle in mandibular arch.

The mean value of angle Ang $2 \mathrm{R}$ in class II maloclussion in different vertical facial patterns was 123.14 in low angle, 130.57 in average angle and 132.57 in high angle in maxillary arch and 138.57 in low angle, 123.43 in average angle and 132.43 in high angle in mandibular arch.

The mean value of angle Ang 2L in class II maloclussion in different vertical facial patterns was 112.14 in low angle, 128.86 in average angle and 133.43 in high angle in maxillary arch and 138.86 in low angle, 131.14 in average angle and 127.29 in high angle in mandibular arch.

The mean value of angle Ang 3R in class II maloclussion in different vertical facial patterns was 76 in low angle, 79.29 in average angle and 74.29 in high angle in maxillary arch and 68.29 in low angle, 72.43 in average angle and 69.29 in high angle in mandibular arch.

The mean value of angle Ang 3L in class II maloclussion in different vertical facial patterns was 80.14 in low angle, 79.14 in average angle and 77.86 in high angle in maxillary arch and 69.29 in low angle, 73 in average angle and 74.86 in high angle in mandibular arch.

The mean value of intercanine distance in class II maloclussion in different vertical facial patterns was 38.07 in low angle, 35.28 in average angle and 34.77 in high angle in maxillary arch and 26.02 in low angle, 27.25 in average angle and 28.41 in high angle in mandibular arch.

The mean value of intermolar distance in class II maloclussion in different vertical facial patterns was 47.72 in low angle, 44.87 in average angle and 46.67 in high angle in maxillary arch and 41.38 in low angle, 40.67 in average angle and 43.74 in high angle in mandibular arch.

Table III AND IV shows the comparison of mean of different parameters of class II malocclusion in three different groups divided based on SN-MP angle (Low, medium and high angle) by one way ANOVA analysis. 
Table $\mathrm{V}$, in class II malocclusion the angle that express the anterior arch form in maxillary arch Ang 1was correlated with the vertical facial pattern. The value of Ang 1 was significant with negative relationship showing $\mathrm{r}=-816$ and $\mathrm{p}$-value .003 . The value of Ang 2R was also highly significant with positive relationship showing $\mathrm{r}=.837$ and $\mathrm{p}$ value .003. The value of Ang 2L was also significant with positive relationship showing $\mathrm{r}=.860$ and $\mathrm{p}$ value .001. The value of Ang 3R and 3L were insignificant with positive relationship showing $\mathrm{r}=.643$ and $\mathrm{p}$ value .056 and $r=.570$ and $\mathrm{p}$ value .132 respectively. The value of intercanine and intermolar distance ratio was significant with negative relationship showing $r=-864$ and p .012.

\section{DISCUSSION}

Vertical facial form is an important element of orthodontic assessment. It is an essential criterion for each orthodontist to understand the relationship between vertical facial height and dental arch width for proper diagnosis and treatment planning. Large variations are found in the vertical dimension and these affect the clinician's approach to successful diagnosis, treatment planning, and mechanics. Errors in the evaluation of patient's facial type can lead to undesirable and sometimes irreversible consequences during orthodontic treatment.

Stability of arch form is one of the most desirable goals of orthodontics, yet unfortunately it is the least understood goal. Arch form tends to return to its original form so the patient's existing arch form appears to be the best guide to the future arch form and stability. The size and shape of arches have a considerable clinical implication in orthodontics especially during diagnosis and treatment planning, as it affects the space available, dental esthetics and stability of dentition. Arch form characterization is desirable since a fundamental goal in orthodontics is the maintenance or successful and stable treatment modification of that arch form.

The most commonly used terms of square, ovoid, tapered or wide or narrow forms of the dental arch have not yet been mathematically defined and therefore, three ratios were chosen across the whole of dental arch so as to better define the dimensions as well as form. Arch forms are affected by arch dimensions and, therefore, comparison of dimensions and form simultaneously bears a lot of advantage in knowing the exact associations between the craniofacial skeleton and the dental arches. Factors such as age, sex and ethnic group are important in making a proper orthodontic treatment plan; another important factor is the facial growth pattern and its several clinical characteristics. It is generally accepted among orthodontists that a relationship exists between vertical facial pattern and the dental arch width.
Nowadays, the use of nickel titanium preformed archwire, in association with straight wire techniques, is widespread. The risk is that the results are not stable because the technique and materials do not fit the patient anatomy. Arch forms are affected by arch dimensions and therefore, comparison of dimensions and forms simultaneously bears a lot of advantage in knowing exact association between craniofacial skeleton and the dental arches. So the objective of present study was to evaluate the correlation between vertical facial pattern and dental arch form in different types of skeletal malocclusion.

In present study value of Anglin skeletal class II malocclusion was decreased from low angle to high angle cases (TABLE I, TABLE II). This is because of downward and backward rotation of the mandible in hyperdivergent facial patterens. This is also in accordance with the study conducted by Kou Xi H[27] who found that the upper and lower incisors of class II, Division 1 malocclusion were labially inclined in vertical growth pattern. When angle Ang 2R, Ang 2L, Ang 3R and Ang 3L were evaluated in skeletal class I malocclusion, it was found that the angular values were increased from low to high angle cases. This may be because as the value of angle Ang 1 decreases, the value of Ang 2R, Ang 2L, Ang 3R and Ang 3L increases as shown in figI.

In the present study, the shape of dental arch was measured on the digital photographs of the patient plaster model by drawing a pentagon inscribed inside the arches as shown in figure 1. The various internal angles inside the maxillary (fig II) and the mandibular arches of pentagon (Ang 1, Ang 2R, Ang 2L, Ang 3R and Ang 3L) and the ratio between the intercanine and intermolar distance was calculated to evaluate the form of dental arch in different types of skeletal malocclusion.

When dental arch forms were correlated with different vertical facial patterns the result analysis showed a change in upper arch shape with an intercanine diameter proportionately smaller in patients with high angles and greater in patients with low angles $(\mathrm{P}<0.05)$ irrespective of malocclusion. The bigger the SN-MP angles were, the narrow is the form of the upper arches. Although the data from the present study showed an inverse trend between SN-MP angle and dental arch widths and it seems that the SN-MP angle might be only one of the contributing factors. There was no statistically significant difference in mandibular arch forms between the three groups with the exception of the angle value Ang. 1. The decrease of this value from low- to high-angle groups should be interpreted as the prevalence of ' $\mathrm{V}$ ' shapes arch form in subjects with high angle and of ovoid arch forms in low angle patients. 
Ankur Sharma et al; Saudi J Oral Dent Res, Sep 2019; 4(9): 657-665

Dental arch form is certainly a multifactorial phenomenon. The data from this study showed an inverse relationship between MP-SN angle and it seems the MP-SN angle might be only one of the contributing factors. Hence, the prediction of dental arch width is generalized and can be influenced by other factors. The relationships between the vertical facial morphology and dental arch widths in untreated Himachali adults have an inverse relationship as in Caucasian population. Hence, irrespective of ethnicity and race of the population group, SN-MP and inter-arch widths can be used as a valuable tool in assessing the vertical and transverse craniofacial and dentoalveolar morphology. This highlights the importance of using individualized archwires according to pretreatment arch form and width for each patient during orthodontic treatment. Since the wide variations in patient arches cannot be met by the few preformed archwire shapes and sizes available, the concept of individualization of archwires is strongly suggested.

\section{CONCLUSIONS}

- Inverse correlation was found between dental arch form and vertical facial pattern indicating narrower arch form in high angle cases and wider arch form in low angle cases.

- As the form of dental arches is associated with the vertical growth patterns, it would be desirable to use individualized arches for each patient.

Table-I: Distribution of mean \& standard deviation of different parameters of a class II malocclusion on maxillary arch in three types of vertical facial patterns (Low, Average \& High)

\begin{tabular}{|c|c|c|c|c|c|c|c|}
\hline Parameters & Vertical Facial Patterns & $\mathbf{N}$ & Mean & Std. Deviation & Std. Error & Minimum & Maximum \\
\hline \multirow[t]{4}{*}{ Ang1 } & $\begin{array}{l}\text { Low Angle } \\
\end{array}$ & 10 & 124.43 & 9.589 & 3.624 & 127 & 146 \\
\hline & Average Angle & 10 & 120.71 & 19.172 & 7.246 & 102 & 144 \\
\hline & High Angle & 10 & 120.66 & 17.141 & 6.479 & 96 & 133 \\
\hline & Total & 30 & 125.67 & 16.614 & 3.626 & 96 & 146 \\
\hline \multirow[t]{4}{*}{ Ang2R } & Low Angle & 10 & 123.14 & 11.187 & 4.228 & 110 & 134 \\
\hline & Average Angle & 10 & 130.57 & 12.660 & 4.785 & 115 & 146 \\
\hline & High Angle & 10 & 132.57 & 10.706 & 4.046 & 124 & 148 \\
\hline & Total & 30 & 128.76 & 11.717 & 2.557 & 110 & 148 \\
\hline \multirow[t]{4}{*}{ Ang2L } & Low Angle & 10 & 112.14 & 1.676 & .634 & 110 & 114 \\
\hline & Average Angle & 10 & 128.86 & 13.031 & 4.925 & 112 & 141 \\
\hline & High Angle & 10 & 133.43 & 11.058 & 4.180 & 116 & 147 \\
\hline & Total & 30 & 124.81 & 13.280 & 2.898 & 110 & 147 \\
\hline \multirow[t]{4}{*}{ Ang3R } & Low Angle & 10 & 76.00 & 5.831 & 2.204 & 69 & 84 \\
\hline & Average Angle & 10 & 79.29 & 2.563 & .969 & 77 & 82 \\
\hline & High Angle & 10 & 74.29 & 3.147 & 1.190 & 72 & 81 \\
\hline & Total & 30 & 76.52 & 4.434 & .968 & 69 & 84 \\
\hline \multirow[t]{4}{*}{ Ang3L } & Low Angle & 10 & 80.14 & 5.699 & 2.154 & 68 & 84 \\
\hline & Average Angle & 10 & 79.14 & 2.116 & .800 & 77 & 82 \\
\hline & High Angle & 10 & 77.86 & 5.398 & 2.040 & 75 & 90 \\
\hline & Total & 30 & 79.05 & 4.555 & .994 & 68 & 90 \\
\hline \multirow{4}{*}{$\begin{array}{c}\text { Inter canine } \\
\text { distance }\end{array}$} & Low Angle & 10 & 38.071 & .4786 & .1809 & 37.6 & 38.7 \\
\hline & Average Angle & 10 & 35.286 & 1.5646 & .5914 & 32.9 & 37.1 \\
\hline & High Angle & 10 & 34.771 & 3.1090 & 1.1751 & 33.3 & 41.8 \\
\hline & Total & 30 & 36.043 & 2.4310 & .5305 & 32.9 & 41.8 \\
\hline \multirow{4}{*}{$\begin{array}{l}\text { Inter molar } \\
\text { distance }\end{array}$} & Low Angle & 10 & 47.729 & .9945 & .3759 & 44.5 & 46.8 \\
\hline & Average Angle & 10 & 44.871 & 2.2904 & .8657 & 42.4 & 47.9 \\
\hline & High Angle & 10 & 46.671 & .8538 & .3227 & 45.4 & 47.6 \\
\hline & Total & 30 & 45.757 & 1.6299 & .3557 & 42.4 & 47.9 \\
\hline \multirow{4}{*}{$\begin{array}{c}\text { Intercanine } \\
\text { Intermolar } \\
\text { distance ratio }\end{array}$} & Low Angle & 10 & .843 & .0535 & .0202 & .8 & .9 \\
\hline & Average Angle & 10 & .786 & .0900 & .0340 & .7 & .9 \\
\hline & High Angle & 10 & .729 & .0756 & .0286 & .7 & .9 \\
\hline & Total & 30 & .786 & .0854 & .0186 & .7 & .9 \\
\hline
\end{tabular}


Ankur Sharma et al; Saudi J Oral Dent Res, Sep 2019; 4(9): 657-665

Table-II: Distribution of mean \& standard deviation of different parameters of a class II malocclusion on mandibular arch in three types of vertical facial patterns. (Low, Average \& High)

\begin{tabular}{|c|c|c|c|c|c|c|c|}
\hline $\begin{array}{r}\text { Paramet } \\
\text { ers }\end{array}$ & $\begin{array}{r}\text { Vertical } \\
\text { Facial } \\
\text { Patterns }\end{array}$ & $\mathbf{N}$ & Mean & Std. Deviation & $\begin{array}{r}\text { Std. } \\
\text { Error }\end{array}$ & Minimum & Maximum \\
\hline \multirow[t]{4}{*}{ Ang1 } & Low Angle & 10 & 134.29 & 1.604 & .606 & 117 & 122 \\
\hline & $\begin{array}{r}\text { Average } \\
\text { Angle }\end{array}$ & 10 & 131.29 & 14.244 & 5.384 & 113 & 147 \\
\hline & High Angle & 10 & 134.71 & 9.087 & 3.435 & 120 & 145 \\
\hline & Total & 30 & 128.43 & 11.505 & 2.511 & 113 & 147 \\
\hline \multirow[t]{4}{*}{ Ang2R } & Low Angle & 10 & 138.57 & 2.070 & .782 & 136 & 141 \\
\hline & $\begin{array}{r}\text { Average } \\
\text { Angle } \\
\end{array}$ & 10 & 123.43 & 3.207 & 1.212 & 119 & 126 \\
\hline & High Angle & 10 & 132.43 & 5.855 & 2.213 & 126 & 144 \\
\hline & Total & 30 & 131.48 & 7.434 & 1.622 & 119 & 144 \\
\hline \multirow[t]{4}{*}{ Ang2L } & Low Angle & 10 & 138.86 & .900 & .340 & 138 & 140 \\
\hline & $\begin{array}{r}\text { Average } \\
\text { Angle }\end{array}$ & 10 & 131.14 & 12.130 & 4.585 & 120 & 145 \\
\hline & High Angle & 10 & 127.29 & 4.536 & 1.714 & 122 & 136 \\
\hline & Total & 30 & 132.43 & 8.652 & 1.888 & 120 & 145 \\
\hline \multirow[t]{4}{*}{ Ang3R } & Low Angle & 10 & 68.29 & .756 & .286 & 67 & 69 \\
\hline & $\begin{array}{r}\text { Average } \\
\text { Angle } \\
\end{array}$ & 10 & 72.43 & 5.028 & 1.901 & 65 & 80 \\
\hline & High Angle & 10 & 69.29 & 1.496 & .565 & 66 & 70 \\
\hline & Total & 30 & 70.00 & 3.421 & .746 & 65 & 80 \\
\hline \multirow[t]{4}{*}{ Ang3L } & Low Angle & 10 & 69.29 & .756 & .286 & 68 & 70 \\
\hline & $\begin{array}{r}\text { Average } \\
\text { Angle }\end{array}$ & 10 & 73.00 & 5.568 & 2.104 & 66 & 79 \\
\hline & High Angle & 10 & 74.86 & 4.220 & 1.595 & 72 & 81 \\
\hline & Total & 30 & 72.38 & 4.522 & .987 & 66 & 81 \\
\hline \multirow{4}{*}{$\begin{array}{l}\text { Inter } \\
\text { canine } \\
\text { distance }\end{array}$} & Low Angle & 10 & 26.029 & .4821 & .1822 & 25.3 & 26.8 \\
\hline & $\begin{array}{r}\text { Average } \\
\text { Angle }\end{array}$ & 10 & 27.257 & 3.0843 & 1.1658 & 23.1 & 30.6 \\
\hline & High Angle & 10 & 28.414 & 1.5214 & .5750 & 25.9 & 30.3 \\
\hline & Total & 30 & 27.233 & 2.1481 & .4688 & 23.1 & 30.6 \\
\hline \multirow{4}{*}{$\begin{array}{l}\text { Inter } \\
\text { molar } \\
\text { distance }\end{array}$} & Low Angle & 10 & 41.386 & .8611 & .3255 & 40.1 & 42.2 \\
\hline & $\begin{array}{r}\text { Average } \\
\text { Angle }\end{array}$ & 10 & 40.671 & 2.2269 & .8417 & 37.8 & 43.7 \\
\hline & High Angle & 10 & 43.743 & .7678 & .2902 & 42.5 & 44.5 \\
\hline & Total & 30 & 41.933 & 1.9223 & .4195 & 37.8 & 44.5 \\
\hline \multirow{4}{*}{$\begin{array}{l}\text { Intercanin } \\
\mathrm{e} \\
\text { Intermola } \\
\mathrm{r} \text { distance } \\
\text { ratio }\end{array}$} & Low Angle & 10 & .600 & .0000 & .0000 & .6 & .6 \\
\hline & $\begin{array}{r}\text { Average } \\
\text { Angle }\end{array}$ & 10 & .686 & .0690 & .0261 & .6 & .8 \\
\hline & High Angle & 10 & .629 & .0488 & .0184 & .6 & .7 \\
\hline & Total & 30 & .638 & .0590 & .0129 & .6 & .8 \\
\hline
\end{tabular}


Ankur Sharma et al; Saudi J Oral Dent Res, Sep 2019; 4(9): 657-665

Table-III: Comparison of mean of different parameters of a class II malocclusion on maxillary arch in three types of vertical facial patterns (Low, Average \& High) by one way ANOVA

\begin{tabular}{|c|c|c|c|c|c|c|}
\hline & & Sum of Squares & df & Mean Square & $\mathbf{F}$ & Sig. \\
\hline \multirow[t]{3}{*}{ Ang1 } & Between Groups & 1000.667 & 2 & 500.333 & 1.992 & $.015^{*}$ \\
\hline & Within Groups & 4520.000 & 18 & 251.111 & & \\
\hline & Total & 5520.667 & 20 & & & \\
\hline \multirow[t]{3}{*}{ Ang2R } & Between Groups & 345.524 & 2 & 172.762 & 1.296 & .298 \\
\hline & Within Groups & 2400.286 & 18 & 133.349 & & \\
\hline & Total & 2745.810 & 20 & & & \\
\hline \multirow[t]{3}{*}{ Ang2L } & Between Groups & 1757.810 & 2 & 878.905 & 8.941 & .142 \\
\hline & Within Groups & 1769.429 & 18 & 98.302 & & \\
\hline & Total & 3527.238 & 20 & & & \\
\hline \multirow[t]{3}{*}{ Ang3R } & Between Groups & 90.381 & 2 & 45.190 & 2.686 & .095 \\
\hline & Within Groups & 302.857 & 18 & 16.825 & & \\
\hline & Total & 393.238 & 20 & & & \\
\hline \multirow[t]{3}{*}{ Ang3L } & Between Groups & 18.381 & 2 & 9.190 & .417 & .665 \\
\hline & Within Groups & 396.571 & 18 & 22.032 & & \\
\hline & Total & 414.952 & 20 & & & \\
\hline \multirow[t]{3}{*}{ Inter canine distance } & Between Groups & 44.134 & 2 & 22.067 & 5.364 & $.015^{*}$ \\
\hline & Within Groups & 74.057 & 18 & 4.114 & & \\
\hline & Total & 118.191 & 20 & & & \\
\hline \multirow{3}{*}{ Inter molar distance } & Between Groups & 11.349 & 2 & 5.674 & 2.444 & .115 \\
\hline & Within Groups & 41.783 & 18 & 2.321 & & \\
\hline & Total & 53.131 & 20 & & & \\
\hline \multirow{3}{*}{ Intercanine Intermolar distance ratio } & Between Groups & .046 & 2 & .023 & 4.114 & .034 \\
\hline & Within Groups & .100 & 18 & .006 & & \\
\hline & Total & .146 & 20 & & & \\
\hline
\end{tabular}

$\mathrm{p}<0.05$ and $\mathrm{p}<0.01$ (significant); $\mathrm{p}<0.01$ (highly significant); $\mathrm{p}>0.05$ (not significant)

Table-IV: Comparison of mean of different parameters of a class II malocclusion on mandibular arch in three types of vertical facial patterns (Low, Average \& High) by one way ANOVA

\begin{tabular}{|c|c|c|c|c|c|c|}
\hline & & Sum of Squares & df & Mean Square & $\mathbf{F}$ & Sig. \\
\hline \multirow[t]{3}{*}{ Ang1 } & Between Groups & 1000.667 & 2 & 500.333 & 1.992 & $.045^{*}$ \\
\hline & Within Groups & 4520.000 & 18 & 251.111 & & \\
\hline & Total & 5520.667 & 20 & & & \\
\hline \multirow[t]{3}{*}{ Ang2R } & Between Groups & 345.524 & 2 & 172.762 & 1.296 & .298 \\
\hline & Within Groups & 2400.286 & 18 & 133.349 & & \\
\hline & Total & 2745.810 & 20 & & & \\
\hline \multirow[t]{3}{*}{ Ang2L } & Between Groups & 1757.810 & 2 & 878.905 & 8.941 & .142 \\
\hline & Within Groups & 1769.429 & 18 & 98.302 & & \\
\hline & Total & 3527.238 & 20 & & & \\
\hline \multirow[t]{3}{*}{ Ang3R } & Between Groups & 90.381 & 2 & 45.190 & 2.686 & .095 \\
\hline & Within Groups & 302.857 & 18 & 16.825 & & \\
\hline & Total & 393.238 & 20 & & & \\
\hline \multirow[t]{3}{*}{ Ang3L } & Between Groups & 18.381 & 2 & 9.190 & .417 & .665 \\
\hline & Within Groups & 396.571 & 18 & 22.032 & & \\
\hline & Total & 414.952 & 20 & & & \\
\hline \multirow[t]{3}{*}{ Inter canine distance } & Between Groups & 44.134 & 2 & 22.067 & 5.364 & $.015^{*}$ \\
\hline & Within Groups & 74.057 & 18 & 4.114 & & \\
\hline & Total & 118.191 & 20 & & & \\
\hline \multirow{3}{*}{ Inter molar distance } & Between Groups & 11.349 & 2 & 5.674 & 2.444 & .115 \\
\hline & Within Groups & 41.783 & 18 & 2.321 & & \\
\hline & Total & 53.131 & 20 & & & \\
\hline \multirow{3}{*}{ Intercanine Intermolar distance ratio } & Between Groups & .046 & 2 & .023 & 4.114 & .034 \\
\hline & Within Groups & .100 & 18 & .006 & & \\
\hline & Total & .146 & 20 & & & \\
\hline
\end{tabular}

$\mathrm{p}<0.05$ and $\mathrm{p}<0.01$ (significant); $<<0.01$ (highly significant); $\mathrm{p}>0.05$ (not significant) 
Ankur Sharma et al; Saudi J Oral Dent Res, Sep 2019; 4(9): 657-665

Table-V: Showed the correlation between dental arch form and vertical facial pattern

\begin{tabular}{|l|r|r|r|}
\hline \multirow{4}{*}{ SN/MP } & & MAXILLA & MANDIBLE \\
\hline \multirow{4}{*}{ Ang1 } & Pearson Correlation & & \\
\cline { 2 - 4 } & P value & Class II & Class II \\
\cline { 2 - 4 } & $\mathrm{N}$ & & \\
\hline Ang2R & Pearson Correlation & -.816 & -.710 \\
\cline { 2 - 4 } & $\mathrm{P}$ value & $.010^{*}$ & $.045^{*}$ \\
\cline { 2 - 4 } & $\mathrm{N}$ & 10 & 10 \\
\hline \multirow{4}{*}{ Ang2L } & Pearson Correlation & .837 & -.281 \\
\cline { 2 - 4 } & $\mathrm{P}$ value & $.003^{*}$ & .541 \\
\cline { 2 - 4 } & $\mathrm{N}$ & 10 & 10 \\
\hline Ang3R & Pearson Correlation & .860 & .531 \\
\cline { 2 - 4 } & $\mathrm{P}$ value & $.003^{*}$ & .062 \\
\cline { 2 - 4 } & $\mathrm{N}$ & 10 & 10 \\
\hline Ang3L & Pearson Correlation & .643 & -.661 \\
\cline { 2 - 4 } & $\mathrm{P}$ value & .056 & .106 \\
\cline { 2 - 4 } & $\mathrm{N}$ & 10 & 10 \\
\cline { 2 - 4 } & Pearson Correlation & .570 & .737 \\
\cline { 2 - 4 } & $\mathrm{P}$ value & .132 & .059 \\
\cline { 2 - 4 } & $\mathrm{N}$ & 10 & 10 \\
\hline Intercanine Intermolar distance ratio & Pearson Correlation & -.810 & -.565 \\
\cline { 2 - 4 } & $\mathrm{P}$ value & $.019^{*}$ & .186 \\
\cline { 2 - 4 } & $\mathrm{N}$ & 10 & 10 \\
\hline
\end{tabular}

\section{REFERENCES}

1. Bhowmik, S. G., Hazare, P. V., \& Bhowmik, H. (2012). Correlation of the arch forms of male and female subjects with those of preformed rectangular nickel-titanium archwires. American Journal of Orthodontics and Dentofacial Orthopedics, 142(3), 364-373.

2. Raberin, M., Laumon, B., Martin, J. L., \& Brunner, F. (1993). Dimensions and form of dental arches in subjects with normal occlusions. American journal of orthodontics and dentofacial orthopedics, 104(1), 67-72.

3. Sampson, P., Little, R. M., Årtun, J., \& Shapiro, P. A. (1995). Long-term changes in arch form after orthodontic treatment and retention. American Journal of Orthodontics and Dentofacial Orthopedics, 107(5), 518-530.

4. Braun, S., Hnat, W. P., Fender, D. E., \& Legan, H. L. (1998). The form of the human dental arch. The Angle Orthodontist, 68(1), 29-36.

5. Enlow, D. H., Hans, M. G., \& McGrew, L. (1996). Essentials of facial growth (pp. 259-260). Philadelphia: Saunders.

6. Boone, G. N. (1963). Archwires designed for individual patients. The Angle Orthodontist, 33(3), 178-185.

7. Burke, S. P., Silveira, A. M., Goldsmith, L. J., Yancey, J. M., Van Stewart, A., \& Scarfe, W. C. (1998). A meta-analysis of mandibular intercanine width in treatment and postretention. The Angle Orthodontist, 68(1), 53-60.

8. Raberin, M., Laumon, B., Martin, J. L., \& Brunner, F. (1993). Dimensions and form of dental arches in subjects with normal occlusions. American journal of orthodontics and dentofacial orthopedics, 104(1), 67-72.

9. Currier, J. H. (1969). A computerized geometric analysis of human dental arch form. American Journal of Orthodontics, 56(2), 164-179.

10. McConaill, M. A., \& Scher, E. A. (1949). Ideal form of the human dental arcade with some prosthetic applications. Dent Rec, 69, 285-302.

11. Proctor, A. D. (1970). Masseter muscle position relative to dentofacial form. Angle Orthod, 40, 3744.

12. Finn, R. A. (1978). Relationship of vertical maxillary dysplasias, bite force, and integrated EMG. In Abstracts of conference on craniofacial research. University of Michigan Center for Human Growth and Development.

13. Proffit, W. R., Fields, H. W., \& Nixon, W. L. (1983). Occlusal forces in normal-and long-face adults. Journal of Dental Research, 62(5), 566570 .

14. Tsunori, M., Mashita, M., \& Kasai, K. (1998). Relationship between facial types and tooth and bone characteristics of the mandible obtained by CT scanning. The Angle Orthodontist, 68(6), 557562.

15. Isaacson, J. R., Isaacson, R. J., Speidel, T. M., \& Worms, F. W. (1971). Extreme variation in vertical facial growth and associated variation in skeletal and dental relations. The Angle Orthodontist, 41(3), 219-229.

16. Woods, G. A. (1950). Changes in width dimensions between certain teeth and facial points during human growth. American Journal of Orthodontics and Dentofacial Orthopedics, 36(9), 676-700. 
Ankur Sharma et al; Saudi J Oral Dent Res, Sep 2019; 4(9): 657-665

17. O'Reilly, T. X. (1951). Deciduous dental arch widths and widths of the face in early childhood. American journal of orthodontics, 37(9), 698-705.

18. Meredith, H. V., \& Higley, L. B. (1951). Relationships between dental arch widths and widths of the face and head. American journal of orthodontics, 37(3), 193-204.

19. Barrow, G. V., \& White, J. R. (1952). Developmental changes of the maxillary and mandibular dental arches. The Angle Orthodontist, 22(1), 41-46.

20. Sillman, J. H. (1964). Dimensional changes of the dental arches: longitudinal study from birth to 25 years. American Journal of Orthodontics, 50(11), 824-842.

21. Joo Ndeph, D. R., Riedel, R. A., \& Moore, A. W. (1970). Pont's index: a clinical evaluation. The Angle Orthodontist, 40(2), 112-118.

22. Wei S.H.Y. (1970). Cranifacial Width Dimensions. Angle Orthod, 40(2):141-147.

23. KNoTT, V. B. (1972). Longitudinal study of dental arch widths at four stages of dentition. The Angle Orthodontist, 42(4), 387-394.

24. Lavelle, C. L. B. (1972). Maxillary and mandibular tooth size in different racial groups and in different occlusal categories. American Journal of Orthodontics and Dentofacial Orthopedics, 61(1), 29-37.

25. Nasby, J. A., Isaacson, R. J., Worms, F. W., \& Speidel, T. M. (1972). Orthodontic extractions and the facial skeletal pattern. The Angle Orthodontist, 42(2), 116-122.

26. Nasby, J. A., Isaacson, R. J., Worms, F. W., \& Speidel, T. M. (1972). Orthodontic extractions and the facial skeletal pattern. The Angle Orthodontist, 42(2), 116-122.

27. Jassim, J. A. (2010). Association between upper dental arch dimensions and facial type in adult with class I normal occlusion. A computerized study. A master thesis, College of Dentistry, Mosul University-Iraq.

28. Lavelle, C. L. B. (1973). Variation in the secular changes in the teeth and dental arches. The Angle Orthodontist, 43(4), 412-421.

29. Chen, K., Zheng, Y., \& Wang, X. (2002). Soft tissue changes of patients with skeletal class II malocclusion after orthodontic and surgical treatments. Hua xi kou qiang yi xue za zhi= Huaxi kouqiang yixue zazhi= West China journal of stomatology, 20(1), 35-38.

30. Ricketts, R.M. (1982). Orthodontic diagnosis and planning. Philadelphia: W.B. Saunders.

31. Kageyama, T., Domínguez-Rodríguez, G. C., Vigorito, J. W., \& Deguchi, T. (2006). A morphological study of the relationship between arch dimensions and craniofacial structures in adolescents with Class II Division 1 malocclusions and various facial types. American journal of orthodontics and dentofacial orthopedics, 129(3), 368-375. 